\title{
A NOVEL APPROACH OF LOCUST BEAN GUM MICROSPHERES FOR COLONIC DELIVERY OF MESALAMINE
}

\section{N. L. SIRISHA ${ }^{1}$, M. CHINNA ESWARIAH ${ }^{2}$, A. SAMBASIVA RAO ${ }^{3}$}

\author{
${ }^{1}$ JNTUH, Hyderabad, Telangana, ${ }^{2}$ Pharmacy College, Kodad, Nalgonda Dt, Telangana), ${ }^{3}$ Sri Indu College of Pharmacy, Sheriguda, \\ Ibrahimpatnam, R. R Dt, Telangana) \\ Email: sirishaphd2011@gmail.com
}

Received: 18 Sep 2017, Revised and Accepted: 28 Nov 2017

\begin{abstract}
Objective: The objective of the present study was to formulate site-specific drug delivery of mesalamine using Locust bean gum.

Methods: The core microspheres were prepared by ionic gelation method using $\mathrm{CaCl}_{2}$ solution and cross-linked with glutaraldehyde and were further coated with pH-sensitive polymer eudragit S-100(1.5-4.5 ml) to retard the drug release in the upper gastrointestinal environment (Stomach and small intestine). Microspheres were characterized by ftir spectroscopy, differential scanning calorimetry and evaluated by scanning electron microscopy (SEM), particle size analysis, entrapment efficiency and in vitro drug release studies in different simulated gastric fluids. Stability studies
\end{abstract} were carried out for one month at $40 \pm 2{ }^{\circ} \mathrm{C} / 75 \pm 5 \% \mathrm{RH}$.

Results: The SEM images revealed the surface morphology was rough and smooth for core and coated microspheres, respectively. The optimized batch (ILBG6) of core microspheres(for $7 \mathrm{hr}$ ), coated microspheres and coated microspheres in presence of rat caecal contents (8\% $/ \mathrm{v}$ ) for $24 \mathrm{hr}$ exhibited $98.44 \pm 2.48,73.58 \pm 3.49 \%$ and $98.28 \pm 4.42$ drug release, respectively. The drug release from all locust bean gum microsphere formulations followed higuchi kinetics. Moreover, drug release from Eudragit S-100 coated microspheres followed the korsmeyer-peppas equation with an fickian kinetics mechanism. Finally, stability studies suggested the change in entrapment efficiency and in vitro drug release of microspheres was minimal, indicating good stability of the formulation.

Conclusion: The microspheres formed using natural polysaccharide locust beangum by ionic gelation method are capable of colon targeting the anti-inflammatory drug, mesalamine for the treatment of ulcerative colitis.

Keywords: Colon-specific, Locust Bean Gum, Mesalamine, Eudragit S-100, Microspheres

(C) 2018 The Authors. Published by Innovare Academic Sciences Pvt Ltd. This is an open access article under the CC BY license (http://creativecommons.org/licenses/by/4.0/)

DOI: http://dx.doi.org/10.22159/ijap.2018v10i1.22638

\section{INTRODUCTION}

Various drug delivery approaches have been explored for successful delivery of drugs to the target site. However, the oral route of administration is considered to be the most convenient and preferred route for a sustained as well as controlled drug delivery system [1]. Controlled drug delivery systems offer numerous advantages compared to conventional dosage forms such as improved efficiency, reduced toxicity and improved patient compliance and convenience [2]. Colonic drug delivery has gained increased attention not just for the delivery of the drugs for the treatment of local diseases associated with the colon but also for its potential for the delivery of proteins and therapeutic peptides. Colon targeting is naturally of value for the topical treatment of diseases of the colon such as Chron's diseases, ulcerative colitis, colorectal cancer, and amoebiasis [3]. 5-Aminosalicylic acid (5-ASA), a typical anti-inflammatory agent is the drug of choice for the treatment of ulcerative colitis.

However, 5-ASA rapidly absorbs from the small intestine and there is little localization of 5-ASA in the colon relative to the small intestine. Thus, it is necessary to develop a colon-specific delivery system for 5-ASA in the treatment of ulcerative colitis [4]. Microspheres form an important part of such novel drug delivery systems [5, 6]. In recent years, considerable attention has been focused on hydrophilic polymers in the design of oral controlled drug delivery systems because of their flexibility to obtain a desirable drug release profile, cost-effectiveness, and broad regulatory acceptance [7]. These polymeric systems have been the potential candidates to deliver bioactive molecules, particularly in controlled release applications [8,9]. Locust bean gum is a high molecular weight branch polysaccharide and is extracted from the seeds of carob tree Ceratonia siliqua. Being non-ionic, it is not affected by $\mathrm{pH}$ or ionic strength. It is dispersible in either hot or cold water, forming a sol having a $\mathrm{pH}$ range 5.4-7.0 [10].
The aim of the present research was to formulate a novel colon targeted drug delivery of mesalamine by using a natural polysaccharide in treating ulcerative colitis because the natural polymer can be degraded only in the colon by the bacterial enzymes produced by the micro flora of colon.

\section{MATERIALS AND METHODS}

Mesalamine was obtained as a gift sample from TherDose Pharma Pvt Ltd, Hyderabad. Locust bean gum was obtained from Nutriroma Pvt. Ltd, Hyderabad. Eudragit S 100 was gifted by Evonik, Germany. sodium alginate, calcium chloride, and glutaraldehyde were purchased from Sigma-aldrich. All reagents used were analytical grade.

\section{Preparation of microspheres by ionic gelation method}

Locust bean gum microspheres containing mesalamine were prepared by ionic gelation method. The drug was dispersed in a solution of locust bean gum in WFI (water for injection) until a uniform dispersion is formed. The microspheres were formed by dropping the bubble free dispersion through a disposable syringe (with a nozzle of 24 gauge) into $4 \%$ calcium chloride solution and allowed curing for $1 \mathrm{~h}$. Later separated, washed and dried in an oven at $50{ }^{\circ} \mathrm{C}$ for $24 \mathrm{~h}$ and stored plastic bags for further use(table 1) [11].

Preparation of eudragit-coated cross-linked locust bean microspheres

Eudragit coating of GA cross-linked locust bean gum microspheres containing MSL were prepared by an oil-in-oil solvent evaporation method. Eudragit-S-100 was dissolved in a $10 \mathrm{ml}$ organic solvent (2:1, ethanol: acetone) to give either $4: 1$ or $8: 1$ ratio. To the above coating solution, $100 \mathrm{mg}$ of drug-loaded microspheres were added. The above dispersion was then poured into $100 \mathrm{ml}$ of liquid paraffin containing $3 \%$ of $\mathrm{w} / \mathrm{v}$ span- 80 . The above system was agitated at $1000 \mathrm{rpm}$ at $40^{\circ} \mathrm{C}$ for $3 \mathrm{~h}$ using a mechanical stirrer (Remi, Mumbai, 
India). The coated microspheres were filtered and washed with nhexane to remove the traces of oily phase on the microspheres and dried overnight in desiccators and packed in plastic bags until further [12].

Table 1: Formulation for mesalamine microspheres

\begin{tabular}{|c|c|c|c|c|c|c|c|}
\hline Formulation & Drug (mg) & Polymer (\%) & GA (ml) & SA (\%) & CC (\%) & SS (rpm) & ST (hr) \\
\hline LBG1 & 100 & 0.25 & 1.5 & 1 & 4 & 100 & 1 \\
\hline LBG2 & 100 & 0.5 & 1.5 & 1 & 4 & 100 & 1 \\
\hline LBG3 & 100 & 1 & 1.5 & 1 & 4 & 100 & 1 \\
\hline
\end{tabular}

*LBG-Locust bean gum, GA-Glutaraldehyde, SA-Sodium alginate, CC-Calcium Chloride, SS-Stirring speed, ST-Stirring time

\section{Optimization of formulation variables}

A three-factor two-level full factorial design was used for the systemic study of the combination of drug and polymers.

The main effects $\left(\mathrm{X}_{1}\right.$ and $\left.\mathrm{X}_{2}\right)$ represent the average result of changing one factor from its low to high values.

The interaction term $\left(\mathrm{X}_{1}, \mathrm{X}_{2}\right)$ shows how the response values change when two factors are simultaneously changed.
A $3^{2}$-factorial design was applied for the experiment where two variables $\left(\mathrm{X}_{1}, \mathrm{X} 2\right)$ were the amount of matrix forming a polymer and a cross-linking agent. The concentration of drug was maintained constant. Further, the quantity of drug and a cross-linking agent and controlled release matrix forming polymer adjusted in combination as like 1:(1.54.5)i.e., $(-1,+1)$ and 1:(0.25-1) respectively. By this way totally 12 formulations were prepared, using Locust bean gum in different concentrations by Ionic gelation method. The levels of polymer and cross-linking agent are set to low and high values are shown in table 2.

Table 2: $3^{2}$-full factorial design: factors, factor levels, and responses

\begin{tabular}{lll}
\hline Factors-in-dependant variables & & $\mathrm{CA}$ in $\mathrm{ml}\left(\mathrm{X}_{2}\right)$ \\
\hline Level & LBG in \%( $\left.\mathrm{X}_{1}\right)$ & 1.5 \\
Low level-1 & 0.25 & 3 \\
Medium level(0) & 0.5 & 4.5 \\
High level+1 & 1.0 & \\
Responses-dependant variables & & \\
$\mathrm{Y}_{1}$ & Particle size in mm & \\
$\mathrm{Y}_{2}$ & Entrapment Efficiency in \% & \\
$\mathrm{Y}_{3}$ & In vitro drug release & \\
\hline
\end{tabular}

*LBG-Locust bean gum, CA-Cross-linking agent

\section{Characterization of microspheres}

\section{Determination of particle size}

Particle size was measured by optical microscopy (INKO, Ambala, India) using a compound microscope. A suspension of MSL (mesalamine) microspheres was allowed to dry on a glass slide to form a thin film and was mounted onto the stage of the microscope and min of 500 particles were measured using an ocular micrometer. Each measurement was made in triplicate.

The mean particle size was calculated using the formula [13]

$$
\mathrm{ADM}=\frac{\mathrm{n} 1 \mathrm{~d} 1+\mathrm{n} 2 \mathrm{~d} 2+\cdots \ldots \ldots \ldots \ldots+\mathrm{nmdm}}{\mathrm{n} 1+\mathrm{n} 2+\cdots \ldots \ldots \ldots+\mathrm{nm}}
$$

\section{Shape and surface morphology}

The shape and surface morphology of microspheres were investigated using Scanning electron microscopy (SEM) (LEO-430, Cambridge, U. K). The microspheres were fixed with carbon-glue on the supports and gold coated in a high vacuum evaporator using a gold sputter module (15Kv) [13].

\section{Determination of encapsulation efficiency}

About $50 \mathrm{mg}$ of microspheres were digested in $10 \mathrm{ml}$ Phosphate buffer saline (PBS, pH-7.4) and extracted completely during $24 \mathrm{~h}$. The solution was centrifuged at $6000 \mathrm{rpm}$. The supernatant filtered through a $0.22 \mu \mathrm{m}$ membrane filter (Millipore) and the amount of mesalamine was measured spectrometrically (Shimadzu, DoubleBeam Spectrophotometer, 150-03, Japan) at $212 \mathrm{~nm}$.

Each determination was made in triplicate $[14,15]$.

Entrapment efficiency $(\%)=\frac{\text { Amount of drug content in microspheres }}{\text { Amount of drug added }} \times 100$

\section{Fourier-transform infrared (FT-IR) spectroscopy}

Fourier-transform infrared spectrum (FTIR) were recorded for 5ASA, locust bean gum, 5-ASA loaded Locust bean gum microspheres using spectrum BX (Perkin Elmer) infrared spectrophotometer. $\mathrm{KBr}$ disks were prepared with samples in them $(2 \mathrm{mg}$ sample/200 $\mathrm{mg}$ $\mathrm{KBr}$ ) with a hydrostatic press at a force of 40 psi for 4 min. The scanning range employed was $450-4000 \mathrm{~cm}^{-1}$.

\section{Differential scanning calorimerty (DSC)}

The thermal behavior of for 5-ASA, locust bean gum, 5-ASA loaded locust bean gum microspheres observed using a differential scanning calorimetry (DSC) Q 10V 8.1 Build 261(Universal V3.9 A TA Instruments) thermal analyzer. The carrier gas used for analysis was argon with a heating rate of $10{ }^{\circ} \mathrm{C} / \mathrm{min}$ with a flow rate of $35 \mathrm{cc} / \mathrm{min}$. The sample size was $5 \mathrm{mg}$ and the temperature range was 0 to $300^{\circ} \mathrm{C}$.

\section{In vitro drug release studies}

The in-vitro drug release studies were performed using USP dissolution rate test (paddle apparatus, $100 \mathrm{rpm}, 37 \pm 0.1^{\circ} \mathrm{C}$ ). $500 \mathrm{mg}$ of microspheres were suspended in $900 \mathrm{ml}$ of dissolution media. For the first two hours in simulated gastric fluid (SGF, pH 1.2; without pepsin), simulated intestinal fluid(SIF, $\mathrm{pH}$ 7.4) mimicking small intestine for $3 \mathrm{hr}$ and replaced with simulated intestinal fluid(SIF,pH6.8) mimicking large intestine environment. Samples withdrawn at different time intervals were quantified using UVVisible Spectrophotometer (Shimadzu, Kyoto, Japan) at $212 \mathrm{~nm}$. Fresh sample $\mathrm{w}$ replaced to maintain sink conditions. The experiment was continued for $24 \mathrm{~h} \mathrm{[16].}$

\section{Preparation of rat caecal medium}

Albino rats weighing $(150 \pm 50)$ g were kept on standard normal diet and water and acclimatized for $10 \mathrm{~d}$. Rats were placed in the cage 
with cage environments having temperatures around $25{ }^{\circ} \mathrm{C}$ to maintain minimum humidity. Rats were separated into groups and placed separately to avoid interaction between them. The condition of the rats was monitored every day and the weight of rats was weighed for a week. $1 \mathrm{ml}$ of $1 \% \mathrm{w} / \mathrm{v}$ solution of locust bean gum in distilled water was administered orally in order to induce the enzymes, which are specified for the biodegradation of the locust bean gum during its passage through the colon. This treatment was continued for 2, 4 and $6 \mathrm{~d}$ in different sets of animals for enzyme induction. Rats were anaesthetized with diethyl ether, dissected and caecal contents were removed in presence of $\mathrm{CO}_{2}$. The caecal contents were then transferred into the simulated colonic fluid (SCF, $\mathrm{pH} 7.0$ ), to produce $2 \%$ caecal dilution. The formulation, which was previously subjected to in vitro drug release studies in SGF (pH 1.2) and SIF ( $\mathrm{pH} 7.5$ ) were immersed in the simulated colonic fluid (SCF, $\mathrm{pH}$ 7.0). To maintain anaerobic environment $\mathrm{CO}_{2}$ gas was bubbled into the medium. The experiments were approved by the Ethical Committee of Anurag Pharmacy College, Faculty of Pharmaceutics, Kodad, Affiliated to JNTUH University, Hyderabad with ethical approval Reg. No. 1712/PO/a/13/CPCSEA [17].

\section{In vitro release in presence of rat caecal contents}

The release of the final optimized formulation was carried out with the addition of rat caecal contents $(2 \% \mathrm{w} / \mathrm{v})$ to observe the effect of the caecal enzymes on the release rate of the drug. Samples obtained at regular intervals were filtered through a $0.22 \mu \mathrm{m}$ membrane filter (Millipore, India) and analyzed using UV-Visible Spectrophotometer
(Shimadzu, Kyoto, Japan) at $212 \mathrm{~nm}$. The experiment was continued for $24 \mathrm{~h}$.

\section{Stability studies}

According to ICH Guidelines, an accelerated stability study has to be carried out on the dosage form at $40 \pm 2{ }^{\circ} \mathrm{C} / 75 \pm 5 \% \mathrm{RH}$. The optimized formulation was placed in the stability chamber at $40 \pm 2$ ${ }^{\circ} \mathrm{C} / 75 \pm 5 \%$ RH for over a period of $30 \mathrm{~d}$. Entrapment efficiency and in vitro drug release studies were carried out and compared with the results of it before conducting the stability [18].

\section{Release kinetic study}

All the release data were fitted to various kinetic models like zero order, first order Korsmeyer-Peppas, Higuchi to find out the mechanism of drug release from the polymeric matrix of microspheres [18].

\section{RESULTS AND DISCUSSION}

\section{Evaluation of optimized formulation of formulation variables}

To study the effect of variables on the characterization of microspheres, different batches were prepared by applying $3^{2}$ full factorial designs. Amount of polymer $\left(\mathrm{X}_{1}\right)$ and cross-linking agent $\left(\mathrm{X}_{2}\right) \mathrm{w}$ varied three levels, low level $(-1)$, medium $(0)$, and high level (+1). The amount of drug and sodium alginate was kept constant. Particle size $\left(\mathrm{Y}_{1}\right), \%$ entrapment efficiency $\left(\mathrm{Y}_{2}\right), \%$ in vitro drug release $\left(\mathrm{Y}_{3}\right)$ were selected dependant variables fig. 1.
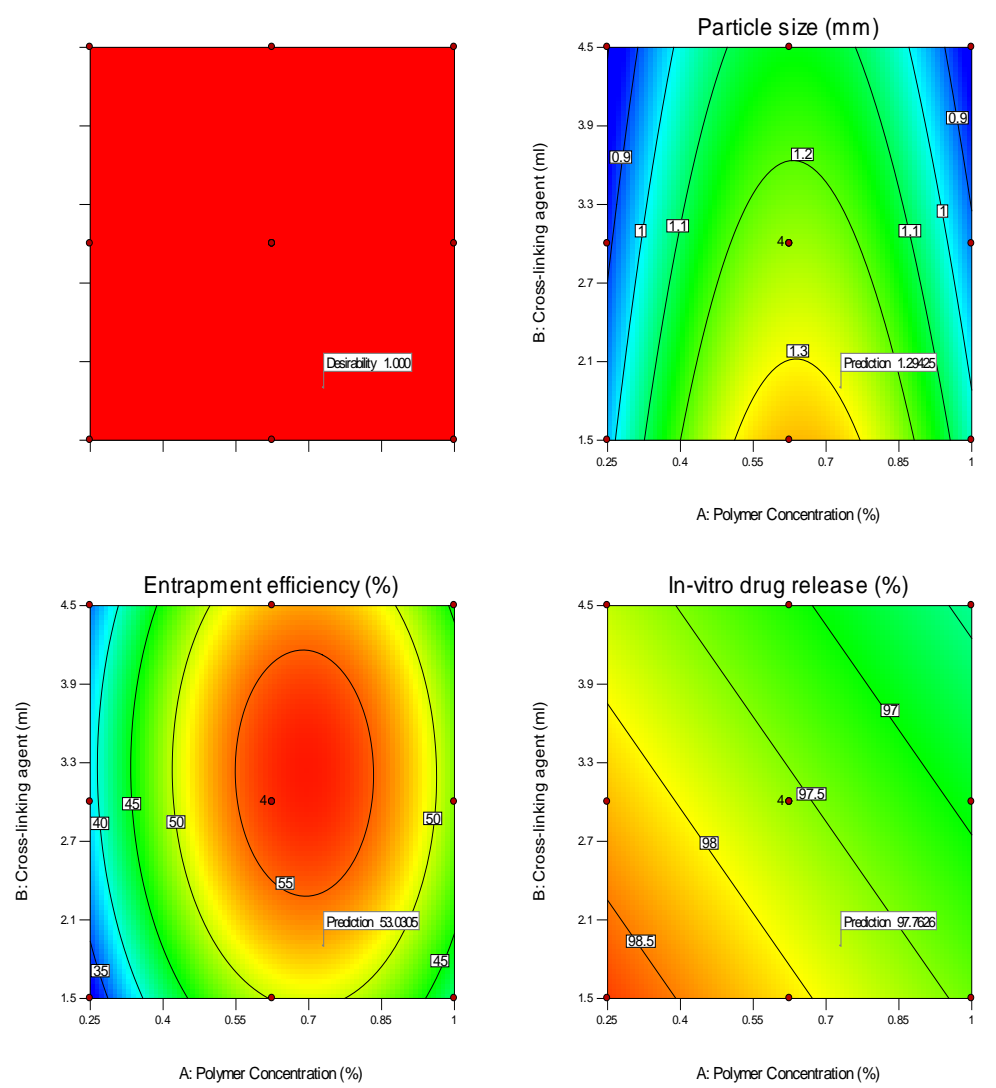

Fig. 1: Surface response graphs for particle size, $\%$ entrapment efficiency, $\%$ in vitro drug release

\section{Particle size, percentage yield, entrapment efficiency}

All the formulated batches were evaluated for particle size, Percentage yield, and entrapment efficiency. Results are given in table 3. Based on the particle distribution results, the microspheres produced did not have a uniform particle size distribution.

This could be caused by the pressure difference in the shedding process of drug and polymer mixtures into the calcium chloride solutions. The average beads diameter showed that the bigger size was obtained while using a higher concentration of natural polysaccharide used. This proved that the big beads size could be affected by natural polysaccharide concentration [19].

The size of the sphere decreased with increase in cross-linking agent concentration because of hardening of the polymer matrix and shrinking of size. The particle size increased with a coating of the microsphere. Faster cross-linking of the microspheres is achieved 
with the increase in cross-linking agent concentration forming rigid microspheres hence prevent the drug loss from the formed spheres.

The entrapment efficiency increased with the increase of polymer concentration and amount of cross-linking agent. The reason may be, increase in polysaccharide concentration leads to increase in the viscosity of aqueous phase and highly viscous phase shows high drug retention capacity by preventing the migration of drug from droplets to surrounding media which result in more encapsulation efficiency [20].

Table 3: Characterization of locust bean microspheres

\begin{tabular}{lllll}
\hline Batch code & LBG $\left(\mathbf{X}_{\mathbf{1}}\right) \mathbf{( \% )}$ & GA $\left(\mathbf{X}_{\mathbf{2}}\right) \mathbf{( m )}$ & PS $(\mathbf{m m})$ & EE (\%) \\
\hline ILBG1 & 0.25 & 4.5 & $0.852 \pm 0.75$ & $38.58 \pm 2.57$ \\
ILBG2 & 0.625 & 3 & $1.26 \pm 0.65$ & $57.42 \pm 1.98$ \\
ILBG3 & 1 & 4.5 & $0.853 \pm 0.77$ & $45.89 \pm 1.08$ \\
ILBG4 & 0.25 & 1.5 & $0.921 \pm 0.33$ & $32.64 \pm 0.57$ \\
ILBG5 & 0.25 & 1.5 & $0.876 \pm 0.57$ & $35.15 \pm 0.65$ \\
ILBG6 & 0.625 & 3 & $1.45 \pm 0.65$ & $50.44 \pm 1.28$ \\
ILBG7 & 1 & 1.5 & $0.934 \pm 0.76$ & $47.25 \pm 2.58$ \\
ILBG8 & 1 & 4.5 & $0.967 \pm 0.66$ & $41.09 \pm 2.56$ \\
ILBG9 & 0.625 & $1.04 \pm 0.74$ & $98.03 \pm 3.74$ \\
\hline
\end{tabular}

*LBG-Locust bean gum, GA-Glutaraldehyde, PS-Particle size, \%EE-Entrapment efficiency, \% IDR-in vitro drug release, *All readings are expressed as mean \pm standard deviation $(\mathrm{n}=3)$

\section{Surface morphology}

Surface morphology of microspheres was taken at $60 \mathrm{x}, 70 \mathrm{x}$ magnifications. Scanning electron microscopy confirmed the spherical shape of the microsphere.

The shape of all formed microspheres was found to be spherical and the surface morphology of the un-coated formulation of microsphere was rough and the coated form of the same formulation was smooth in the surface. This might be because of the smoothing of the surface by the eudragit coating solution. (fig. 2).

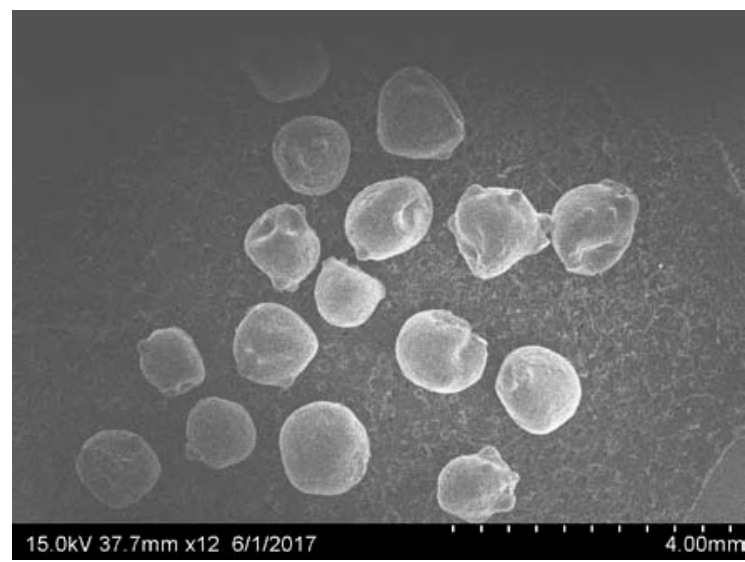

a)

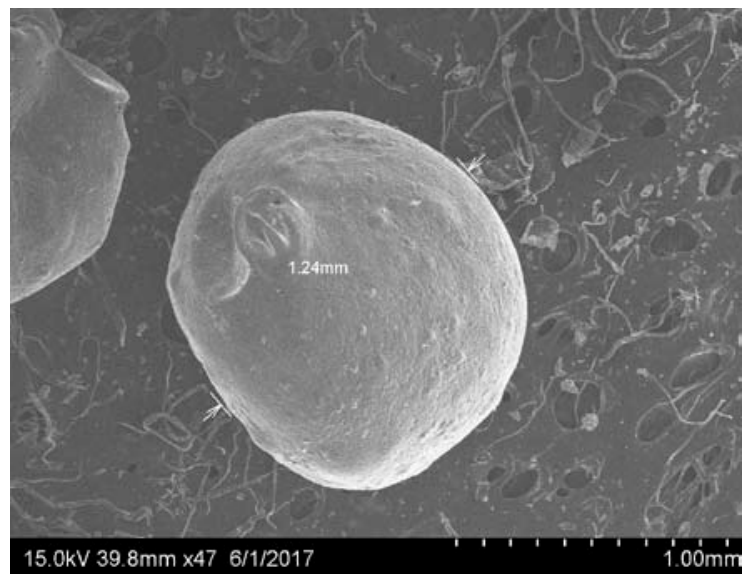

b)

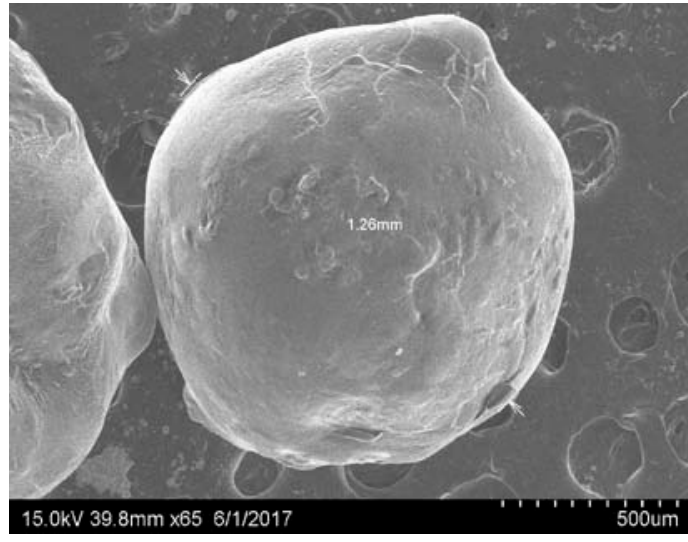

c)

Fig. 2: Scanning electron microscopy of a) group of drug loaded LBG-microspheres, b) surface morphology of un-coated drugloaded microspheres, c) coated drug loaded microsphere

\section{FTIR studies}

To investigate the interaction between drug and polymer FTIR studies were carried out. The FTIR Spectra for the Pure drug, Polymer, Microsphere formulation were analyzed. The FTIR Spectrum of the pure drug shows a characteristic peak at 1266.2 cm-1 for C-N stretching vibration, $1794.7 \mathrm{~cm}-1$ and $1487.9 \mathrm{~cm}-1$ indicating the presence of benzene ring and at $1602.3 \mathrm{~cm}-1$ indicates for $\mathrm{N}-\mathrm{H}$ in-plane bending. Other peaks observed are $1651.0 \mathrm{~cm}-1$ for $\mathrm{C}=0$ stretching vibration of carboxylic acid and $2982.8 \mathrm{~cm}-1$ for acryl C-H stretching. The spectrum was overlapped and with the drug-loaded microsphere formulation and was observed that no new bond was formed and there was no interaction with polymer indicating good compatibility between the drug and the polymer (fig. 3).

\section{DSC studies}

The DSC studies carried out to observe the thermal behavior of drugloaded microspheres whether the drug was encapsulated in them or not. The characteristic endothermic peak appeared at $298.38^{\circ} \mathrm{C}$ and $163.50{ }^{\circ} \mathrm{C}$ for Mesalamine and Locust bean gum respectively was disappeared in drug-loaded microsphere formulation but had a characteristic new peak at $207.78{ }^{\circ} \mathrm{C}$ (fig. 4). A significant peak change in DSC thermogram confirmed that mesalamine had experienced chemical interaction and had been entrapped into the microsphres. This explains the molecular encapsulation of mesalamine in the matrix of the polymer. 

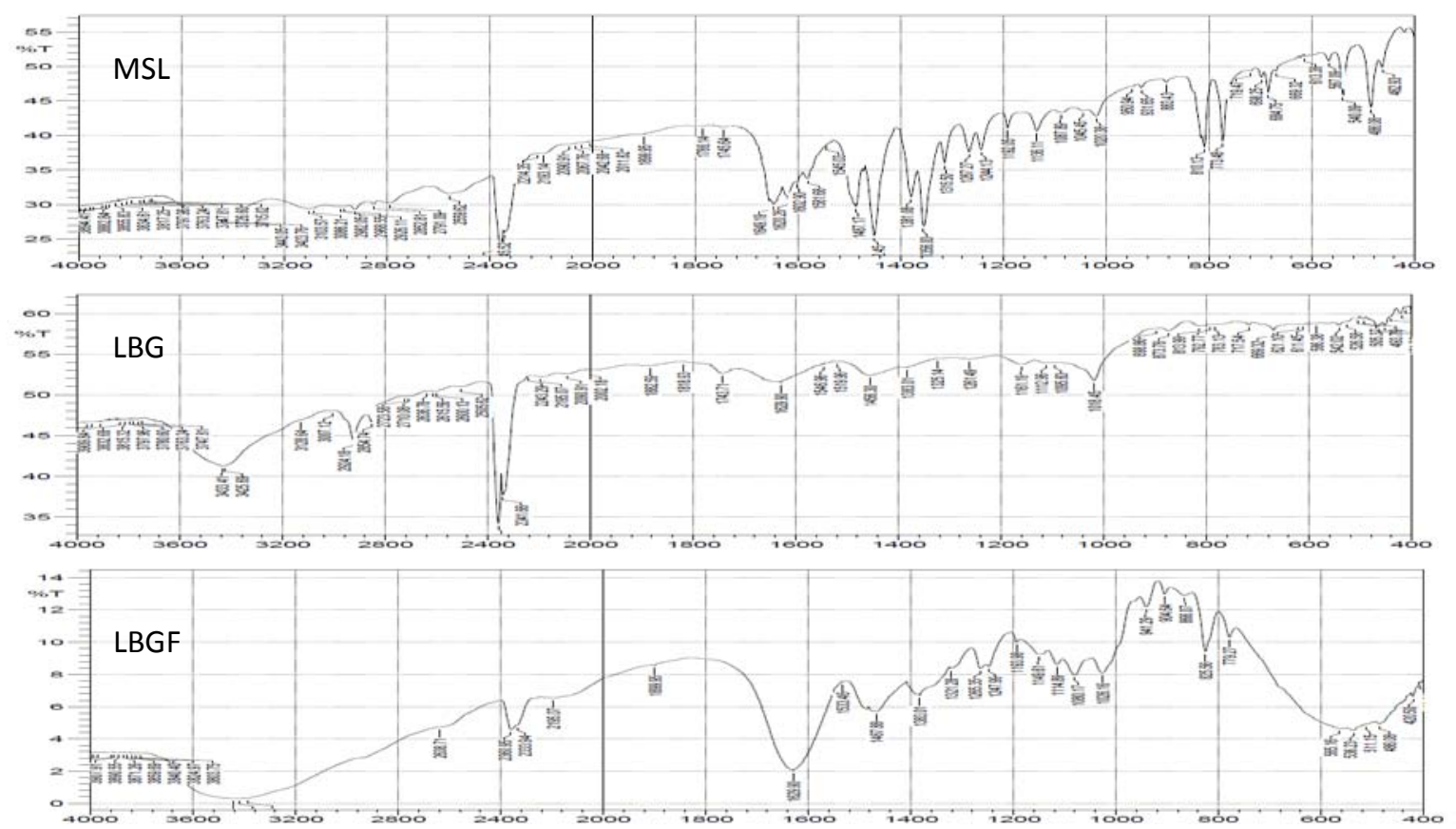

Fig. 3: FTIR results of pure drug, locust bean gum, MSL-loaded locust bean gum microspheres, *MSL-mesalamine, LBG-locust bean gum, LBGF-locust bean gum formulation

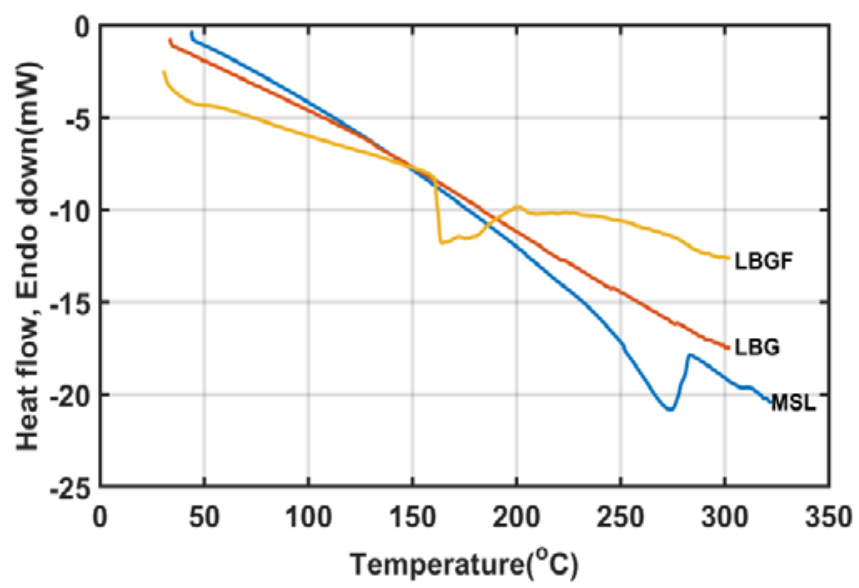

Fig. 4: DSC curves of the pure drug, locust bean gum, MSL-loaded locust bean gum microspheres, *MSL-mesalamine, LBG-locust bean gum, LBGF-locust bean gum formulation

\section{In vitro drug release}

All formulation batches were subjected to in vitro drug release studies in SGF (pH-1.2) for first $2 \mathrm{~h}$ and SIF ( $\mathrm{pH}-7.4)$ for $3 \mathrm{~h}$ later and in SIF (pH-6.8) up to $24 \mathrm{~h}$ to observe the drug release of the microspheres in the stomach, small intestine, large intestine respectively. The amount of drug release for the optimized formulation in first $5 \mathrm{~h}$ studies showed that the polymer matrix remained intact in the stomach and small intestine environment and the gelling property of the polymer retards the drug release from the matrix. There was an initial release of drug in the first $2 \mathrm{~h}$ of the studies indicating the un-entrapped drug on the surface of the matrix of the microsphere but later due to the formation of the viscous gel layer around the sphere, the drug release was retarded. The polymer matrix could retard the drug release up to around $7 \mathrm{~h}$. To retard the drug release up to $24 \mathrm{~h}$ the optimized formulation was coated with Eudragit S-100 in three different concentrations (4\% $\mathrm{w} / \mathrm{v}, 8 \% \mathrm{w} / \mathrm{v}, 15 \% \mathrm{w} / \mathrm{v}$ ) and the drug release studies were performed. Of all the formulated batches ILBG6 was selected as the optimized formulation which showed good entrapment efficiency. Due to the coating of the microsphere, the drug release was retarded for more than $24 \mathrm{~h}$. Of the three concentrations of coating solutions formulation coated with $8 \% \mathrm{w} / \mathrm{v}$ showed good retardation and optimized release of drug for $24 \mathrm{~h}$, while the $4 \% \mathrm{w} / \mathrm{v}$ and $15 \% \mathrm{w} / \mathrm{v}$ formulation had a fast release before $24 \mathrm{~h}$ and retardation which had very low release even after $24 \mathrm{~h}$ respectively. The In vitro drug release studies were performed with and without rat caecal contents for the final optimized formulation and the release was compared.

The amount of drug release from the formulation was found to be higher in the presence of rat caecal contents $(98.28 \pm 4.42) \%$ due to the degradation of the polymer matrix by colonic enzymes released by colonic bacteria than without rat caecal contents $(73.58 \pm 3.49)$ in the SIF medium (fig. 5). Since being non-ionic in nature locust bean gum was not affected by $\mathrm{pH}$ or ionic strength which makes it efficient in retard the drug release in the gastric and intestinal $\mathrm{pH}$ and once reaches the large intestine the polymer gets degraded by the microfloral enzymes of colonic bacteria which cause the breakdown of the 1, 4-linked $\beta$-D-mannopyranose units of natural polymer and thus cause the release of the drug locally in colon. To extend the retardation of drug release the optimized formula was coated with $\mathrm{pH}$-sensitive polymer eudragit S-100 which does not 
degrade below the $\mathrm{pH}$ 7. The presence of rat caecal contents increase the drug release because of the bacterial enzymes present in them. The polymer concentration and cross-linking agent amount had a significant effect on the size, shape, surface morphology and entrapment efficiency and in vitro drug release profiles of the formed microspheres. The molecular structure of the polymer and the polymer coating of drug release and the rat caecal contents have a significant effect on the drug release from the microspheres.

\section{Stability studies}

The entrapment efficiency and in vitro drug release had no significant decrease when compared with the formulation before stability studies. Hence the formulations are found to be stable.

\section{Release kinetic study}

All the release data were fitted to various kinetic models like zero order, first order Korsmeyer-Peppas, Higuchi to find out the mechanism of drug release from the polymeric matrix of microspheres. The in vitro release from the core microsphere (Locust bean gum microsphere) was found to be following Higuchi diffusion since the plots provide the highest linearity.

For all LBG-microspheres, then value as per Korsmeyer-Peppas model was found to be between 0.44 and 0.82 , indicating anomalous release behavior of the drug, i.e., both diffusion and dissolution of the hydrated polymer matrix might be responsible for drug release from the microsphere. Coated microspheres followed Fickian kinetics with the value $n<0.44$ as per the Korsmeyer-Peppas model which might be due to relaxation of the polymer matrix; followed by the diffusion matrix (table 4).

The release of drug from the coated microspheres is by the first relaxation of the matrix by dissolution of polymer matrix structure further diffusion through the pores formed in the matrix.

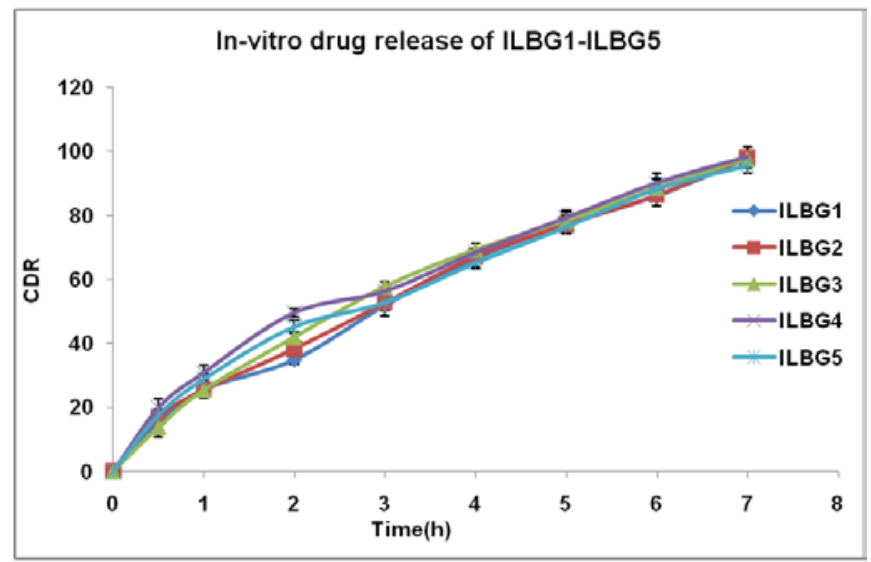

a)

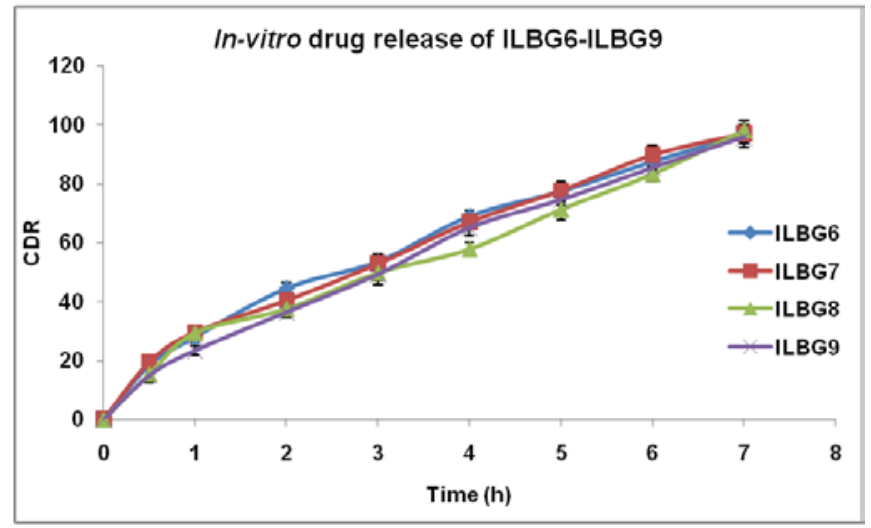

b)

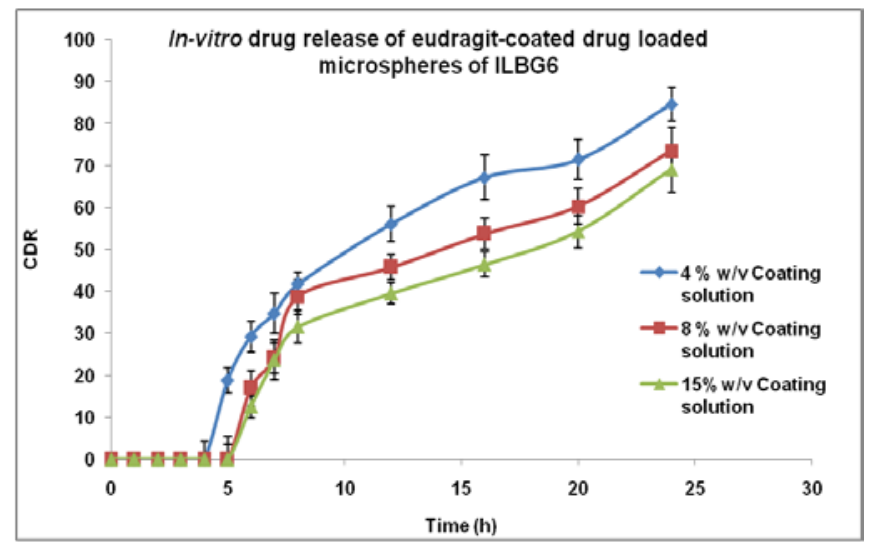

c) 


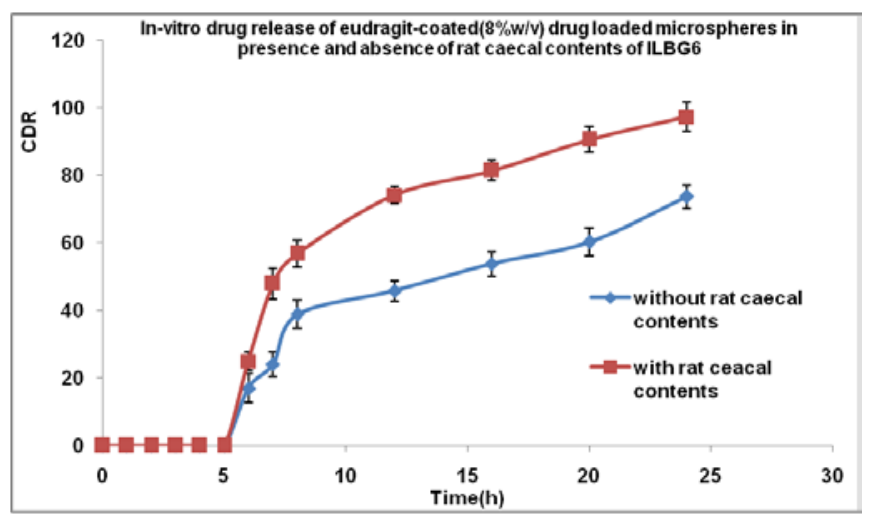

d)

Fig. 5: In vitro drug release curves of a) ILBG1-ILBG5,b) ILBG6-ILBG9,c) Eudragit-coated drug-loaded microspheres of ILBG6,d) Eudragitcoated $(8 \% \mathrm{w} / \mathrm{v})$ drug-loaded microspheres in presence and absence of rat caecal contents of ILBG6, ${ }^{*} \mathrm{All}$ readings are expressed as mean \pm standard deviation $(n=3),{ }^{*} \mathrm{CDR}$-Cumulative percentage drug release

Table 4: Comparison of different dissolution kinetic models

\begin{tabular}{lllll}
\hline Formulation & Zero-order & First order & Higuchi & Korsmeyer-Peppas \\
\cline { 2 - 5 } & $\mathbf{R}^{\mathbf{2}}$ & $\mathbf{R}^{\mathbf{2}}$ & $\mathbf{R}^{\mathbf{2}}$ & $\mathbf{\mathbf { R } ^ { \mathbf { 2 } }}$ \\
\hline ILBG1 & 0.894 & 0.976 & 0.980 & 0.959 \\
ILBG2 & 0.898 & 0.987 & 0.993 & 0.986 \\
ILBG3 & 0.942 & 0.896 & 0.992 & 0.984 \\
ILBG4 & 0.946 & 0.966 & 0.996 & 0.980 \\
ILBG5 & 0.971 & 0.974 & 0.989 & 0.983 \\
ILBG6 & 0.939 & 0.987 & 0.990 & 0.985 \\
ILBG7 & 0.954 & 0.967 & 0.979 & 0.961 \\
ILBG8 & 0.969 & 0.950 & 0.976 & 0.67 \\
ILBG9 & 0.964 & 0.965 & 0.976 & 0.968 \\
\end{tabular}

\section{CONCLUSION}

The ionic gelation method was proposed for the preparation of locust bean gum microspheres was found to be a good technique to entrap mesalamine and was capable of targeting the release of the anti-inflammatory drug (mesalamine) in the colon for the management of colitis. Various parameters studied such as particle size, entrapment efficiency, in vitro drug release the capability of locust bean gum microspheres in delivering the therapeutic moiety to the colon. Ther locust bean gum microspheres formulations require for further in vivo studies to scale up the technology.

\section{ACKNOWLEDGEMENT}

The authors would like to thank authority The Dose Pharma Pvt Ltd for the gift sample of drug and facility.

\section{AUTHORS CONTRIBUTIONS}

All the authors have contributed equally.

\section{CONFLICTS OF INTERESTS}

Declared none

\section{REFERENCES}

1. Chawla, Pooja Sharma, Pravin Pawar. Eudragit S-100 coated sodium alginate microspheres of naproxen sodium: Formulation, optimization and in vitro evaluation. Acta Pharm 2012;62:529-45.

2. Arya RKK, Singh R, Juyal V. Mucoadhesive microspheres of famotidine: preparation characterization and in vitro evaluation. Int J Eng Sci Tech 2010;2:1575-80.

3. MK Chourasia, SK Jain. Pharmaceutical approaches to colon targeted drug delivery systems. J Pharm Pharm Sci 2003;6:33-66.

4. Dinesh Kaushik, Kavita Sharma, Satish Sardana. Colon targeting guar gum microspheres of 5-aminosalicylic acid: evaluation of various process variables, characterization, and in vitro drug release. Indian J Pharm Education Res 2016;50:106-14.

5. Banerjee S, Chaurasia G, Pal DK, Ghosh A, Kaity S. Investigation on crosslinking density for development of novel interpenetrating polymer network (IPN) based formulation. J Sci Ind Res 2010;69:777-84.

6. Burugapalli K, Bhatia D, Koul V, Choudhary V. Interpenetrating polymer networks based on poly (acrylic acid) and gelatin. I: swelling and thermal behavior. J Appl Polym Sci 2001;82:217-27.

7. Santhosh Kumar Mankala, Nishanth Kumar Nagamalli, Ramakrishna Raprla, Rajyalaxmi Kommula. Preparation and characterization of mucoadhesive microcapsules of gliclazide with natural gums. S J Pharm Sci 2011;4:38-48.

8. Hejazi R, Amiji M. Chitosan based gastrointestinal delivery systems. J Controlled Release 2003;89:151-65.

9. Itokazu M, Yamamoto K, Yang WY, Aoki T, Kato N, Watanabe K. The sustained release of antibiotics from freeze-dried fibrinantibiotic compound and efficacies in rat model of osteomyelitis. Infection 1997;25:359-63.

10. WM Obeidat, JC Price. Preparation and evaluation of Eudragit $S$ 100 microspheres as pH-sensitive release preparations for piroxicam and theophylline using the emulsion-solvent evaporation method. J Microencapsul 2006;23:195-202.

11. Kuldeep Hemraj Ramteke, Varsha Balaji Jadhav, Nilesh Shrikant Kulkarni, Amol Rameshrao Kharat, Sonali Bhima Diwate. Preparation, evaluation, and optimization of multiparticulate system of mebendazole for colon targeted drug delivery by using natural polysaccharides. Adv Pharm Bull 2015;5:361-71.

12. Thiruganesh Ramasamy, Hima Bindu Ruttala, Suresh Shanmugam, Subbiah Kandasamy Umadevi. Eudragit-coated aceclofenac-loaded pectin microspheres in chronopharmacological treatment of rheumatoid arthritis. Drug Delivery 2013;20:65-77.

13. Umadevi SK, Thiruganesh R, Suresh S, Reddy KB. Formulation and evaluation of chitosan microspheres of aceclofenac for 
colon-targeted drug delivery. Biopharm Drug Dispos 2010;31:407-27.

14. Gawade P, Agrawal S. Design and characterization of eudragit coated Chitosan microspheres of deflazacort for colon targeting. J Pharm Res 2012;5:4867-70.

15. Chawla A, Sharma P, Pawar P. Eudragit S-100 coated sodium alginate microspheres of naproxen sodium: formulation, optimization and in vitro evaluation. Acta Pharm 2012; 62: $529-45$.

16. Kaushik D, Sardana S, Mishra D. In vitro characterization and cytotoxicity analysis of 5-fluorouracil loaded chitosan microspheres for targeting of colon cancer. Indian J Pharm Educ Res 2010;44:274-82.
17. Bashardoust N, Jenita JL, Zakeri-Milani P. Preparation and in vitro investigation of chitosan compressed tablets for colon targeting. Adv Pharm Bull 2011;1:87-92.

18. Costa P, Sousa Lobo JM. Modeling and comparison of dissolution profiles. Eur J Pharm Sci 2001;13:123-33.

19. Raditya Iswandana, Kurnia Sari Setio Putri, Randika Dwiputra, Tryas Yanuari, Santi Purna Sari, Joshita Djajadisastra. Formulation of chitosan tripolyphosphate-tetrandrine beads using ionic gelation method: in vitro and in vivo evaluation. Int ] Appl Pharm 2017;9:109-15.

20. Vikram Kumar Sahu, Nitin Sharma, Pratap Kumar Sahu, Shubhini A Saraf. Formulation and evaluation of floating-mucoadhesive microspheres of novel natural polysaccharide for site-specific delivery of ranitidine hydrochloride. Int J Appl Pharm 2017;9:15-9. 